\title{
STRATEGI PARIWISATA DALAM MENINGKATKAN KUNJUNGAN WISATA DI KABUPATEN JAYAPURA, PROPINSI PAPUA
}

\author{
Demiut Behabol1) \\ Junianto Tjahjo Darsono2) \\ Harianto Respati ${ }^{3)}$ \\ Jl. Terusan Raya Dieng No.59 Malang
}

Program Pascasarjana Universitas Merdeka Malang

Korespondensi dengan Penulis:

Pascasarjana Unmer Malang: Telp: 0341-582881

\begin{abstract}
Jayapura district has many attractions that can be developed. Tourism in Jayapura that became a tourist visit such as the monument of General Douglas Mac Arthur in Ifar Mountains, Kampung Pulau Asei Travel, Tourism Village Tourism Village Abar and Tablanusu. The tourism sector is positioned as a strategic sector in the national development as well as the one source of income. This sector needs to be developed because it is considered as an effective tool for the improvement of the local economy such as employment and development of the regions that have the potential as a tourist attraction. Tourism is something that is needed by every human being because the longer a person is engaged in his work, the opportunity to calm the mind with a traveled the main choice. This study used a qualitative descriptive research is generally done with the primary goal, namely describe systematically the scientific information derived from the subject and object of research. Descriptive study focuses on a systematic explanation of the facts obtained during research conducted and the characteristics of the object being studied. The analysis technique used SWOT analysis is "Assessment / assessment of the identification of the situation to find out if a condition is said to be the strengths, weaknesses, opportunities or threats. Internal factors that support the development of tourism Jayapura district are: tourist attraction, in the form of nature, especially the beaches in Jayapura District, Enchantment Tours, beautiful, natural beauty tours that have not been exposed to pollution, diversity of shore excursions, many beaches are scattered in the district of Jayapura, beautiful scenery, cultural attractions from various regions surrounding the tour in Jayapura. External factors that favor the development of tourism Jayapura District, among others: travel business opportunities in the tourist area in Jayapura.
\end{abstract}

Keyword: Strategy, Tourism, Visitation, Jayapura

Pembangunan kepariwisataan pada umumnya diarahkan sebagai sektor andalan untuk mendorong pertumbuhan ekonomi, peningkatan pendapatan daerah, memberdayakan perekonomian masyarakat, 
memperluas lapangan kerja dan kesempatan berusaha, serta meningkatkan pengenalan dan pemasaran produk dalam rangka meningkatkan kesejahteraan masyarakat. Pengembangan kawasan wisata harus merupakan pengembangan yang terencana secara menyeluruh sehingga dapat diperoleh manfaat yang optimal bagi masyarakat.

Pemerintah Kabupaten (Pemkab) Jayapura Papua melalui Dinas Pariwisata mengembangkan lima obyek wisata potensial di daerah itu agar lebih banyak dikunjungi wisatawan domestik maupun mancanegara. Kabupaten Jayapura memiliki banyak obyek wisata yang dapat terus dikembangkan. Obyek wisata di Kabupaten Jayapura yang menjadi tempat kunjungan wisatawan seperti Tugu Jenderal Douglas Mac Artur di Ifar Gunung, Kampung Wisata Asei Pulau, Kampung Wisata Abar dan Kampung Wisata Tablanusu.

Kunjungan wisata ke Jayapura selama ini terdongkrak Festival Danau Sentani dan terus meningkat dari sekitar 72.000 orang tahun 2012 menjadi sekitar 87.000 orang tahun 2013. Khusus wisatawan mancanegara meningkat dari 1.012 orang (2012) menjadi 1.268 orang (2013). Untuk memperkuat pesona Danau Sentani, Pemerintah Kabupaten Jayapura membentuk desa wisata sagu di tepian danau itu dan wisata gerabah di kampung Abar, salah satu pulau di Danau Sentani. Jalur jalan dari bandara ke Sentani dan Jayapura pun diperbaiki dan semakin layak.

Melihat banyaknya potensi wisata yang terdapat dikabupaten Kabupaten Jayapura, namun pemerintah belum bisa mengembangkan potensi-potensi pariwisata ini. Potensi wisata ini banyak yang terbengkalai sehingga jumlah pengunjung semakin lama mengalami penurunan. Hal tersebut terjadi karena keadaan sumber daya manusia yang masih rendah dalam hal menangkap peluang sektor pariwisata, dimana sektor pariwisata belum mampu diandalkan dalam peningkatan kesejahteraan masyarakat.

Kondisi ini diantaranya disebabkan oleh kurangnya strategi promosi pariwisata yang masih 
kurang oleh pemerintah Kabupaten Kabupaten Jayapura, sehingga masih banyak masyarakat Kabupaten Kabupaten Jayapura belum mengetahui potensi-potensi pariwisata yang terdapat di Kabupaten Kabupaten Jayapura sendiri. Promosi pariwisata di Kabupaten Kabupaten Jayapura masih tergolong kurang efektif yang terlihat dari belum adanya peningkatan arus kunjungan wisatawan di Kabupaten Jayapura yang signifikan.

Pemerintah daerah telah membuat strategi guna pengembangan pariwisata di Kabupaten Jayapura, namun strategi ini belum mampu memberi kemajuan yang signifikan dalam mengoptimalkan potensi yang ada dengan belum dilibatkannya masyarakat lokal, sehingga untuk mengoptimalkan potensi yang ada serta meningkatkan kunjungan wisatawan diperlukan suatu strategi lain dalam upaya untuk mengembangkan sektor pariwisata di Kepulauan Banda, dimana strategi ini dijaring melalui persepsi wisatawan dan masyarakat lokal. Strategi ini diharapkan mampu mengoptimalkan dan menjawab kebutuhan wisatawan serta dapat meningkatkan pendapatan masyarakat lokal, disamping tetap mempertahankan keberlangsungan dalam pembangunan pariwisata.

\section{METODE}

Berdasarkan sifat permasalahan dan tujuan yang ingin dicapai, penelitian ini dikategorikan atau berjenis deskriptif kualitatif. Data penelitian ini dikumpulkan dalam kondisi yang asli atau alamiah (natural setting). Instrumen kunci dalam penelitian ini adalah peneliti sebagai alat penelitian, artinya peneliti sebagai alat utama pengumpul data dengan metode pengumpulan data berdasarkan observasi yaitu teknik yang menuntut adanya pengamatan dari si peneliti baik secara langsung ataupun tidak langsung terhadap obyek penelitiannya. Dalam penelitian ini observasi secara deskriptif yaitu peneliti berusaha untuk mengamati merekam mencatat dan mendokumentasikan keadaan pantai Kabupaten Jayapura. Pengumpulan data juga dilakukan dengan deep interview, merupakan suatu tehnik mengumpulkan data dengan 
mengajukan pertanyaan secara langsung kepada informan oleh pewawancara. Dalam penelitian ini observasi dan dokumentasi mulai dilakukan pada bulan Desember 2014 hingga akhir Januari 2015 dengan memilih lokasi yang berpotensi untuk kegiatan wisata bahari dan lokasi yang sering dikunjungi wisatawan yang memiliki kegiatan wisata bahari. Area sampling dalam penelitian ini dibagi berdasarkan kegiatan ataupun perubahan yang terjadi di pantai Kabupaten Jayapura, untuk kegiatan olahraga air di lakukan di Kabupaten Jayapura. Untuk kegiatan rekreasi air di pantai Aston dan pantai Kabupaten Jayapura, area sampling untuk kegiatan menyelam dilakukan di pesisir Kabupaten Jayapura itu observasi dan dokumentasi dilakukan di seluruh pesisir Kabupaten Jayapura dengan batasan yang sudah di tetapkan. Penyebaran lembar pertanyaan diberikan kepada wisatawan yang telah menikmati aktivitas wisata bahari, dan wawancara mendalam dilakukan pada lokasi yang sudah ditentukan dengan pencarian sampel dipilih secara sengaja purposive. untuk dapat memberikan jawaban secara jelas keadaan pesisir Kabupaten Jayapura dan wisata baharinya baik keadaan yang terdahulu saat ini dan maupun yang akan datang, sampel itu terdiri dari informan dari Kabupaten Jayapura, kelompok nelayan, orangorang yang sudah professional dalam aktivitas bahari baik jenis selam maupun olahraga air.

Dihitung yang berhubungan dengan wisata bahari dan perkembangan di pantai Kabupaten Jayapura seperti data jumlah kunjungan wisatawan jumlah wisata tirta, jenis atraksi, aktivitas wisata bahari dan jumlah kunjungan wisatawan dan lain-lain. Sumber data penelitian pada dasarnya ada 2, yaitu sumber data primer dan sumber data sekunder. Data primer dalam penelitian ini yaitu data yang diperoleh dari data awal yang diberikan kepada pihak Pariwisata Kabupaten Jayapura yang kemudian diolah lebih lanjut oleh peneliti sedangkan data sekunder dalam penelitian ini adalah dokumendokumen perusahaan, hasil penelitian terdahulu, buku literatur, dan sebagainya. Teknik pengumpulan data yang digunakan dalam penelitian ini 
yaitu wawancara dan dokumentasi. Teknik analisis data yang digunakan yaitu analisis SWOT.

\section{HASIL DAN PEMBAHASAN}

1. Analisis Nilai-Nilai Strategis Pariwisata Kabupaten Jayapura

Karakteristik Kabupaten Jayapura yang memiliki potensi wisata yang cukup besar dan masing-masing mempunyai karakteristik senidri-sendiri. Pada wisata religi yaitu obyek wisata pantai yang diunggulkan di Kabupaten Jayapura selalu ramai dikunjungi para peziarah dan mampu memberikan banyak peluang kepada masyarakat sekitar obyek wisata tersebut untuk membuka usaha di sekitar obyek wisata tersebut. Kemudian pada wisata alam yaitu pada obyek wisata gunung rawa dan kebun kopi jollong yang mempunyai keindahan alam yang mendukung bagi pariwisata Kabupaten Jayapura.

Obyek wisata religi di Kabupaten Jayapura merupakan obyek wisata yang mempunyai jumlah arus kunjungan yang lebih ramai dari pada obyek wisata lain di Kabupaten Jayapura. Obyek wisata religi tersebut adalah obyek wisata makam Syeh Jangkung dan obyek wisata Syeh Mutamakin. Pada obyek wisata religi/ziarah tersebut sangat potensial untuk dikembangkan karena kondisi masyarakat Kabupaten Jayapura yang agamis. Hal tersebut terbukti dengan selalu ramainya arus.

\section{Faktor Pendukung dan} Penghambat

\section{a. Faktor Pendukung}

1) Keindahan alam Kabupaten Jayapura yang belum begitu terekspose kepada khalayak umum di luar Papua.

2) Banyaknya buku pengetahuan tentang Papua yang dibuat oleh warga negara asing.

3) Jayapura sebagai ibukota Provinsi Papua memiliki 
potensi untuk dijadikan destinasi wisata utama di Papua sebagai etalase / pintu masuk para wisatawan.

4) Kekuatan destinasi Kabupaten Jayapura yang unik dan indah karena di dalam kota ada kampung, di dalam kota ada teluk di dalam teluk (Teluk Youtefa), daerah yang berbukit-bukit dengan posisi gunung yang berdekatan dengan pantai, serta merupakan lokasi bersejarah semasa Perang Dunia ke-2.

5) Masyarakat Jayapura yang ramah kepada wisatawan dan memiliki keaneragaman suku yang masih dipimpin oleh Ondoafi (kepala suku) di setiap kampungnya.

\section{b.Faktor Penghambat}

1) Sulitnya mencari informasi mengenai tempat wisata di Jayapura.

2) Masih kurangnya minat masyarakat untuk berkunjung ke Jayapura karena biaya dan letaknya yang jauh berada di wilayah ujung Timur Indonesia.

3) Kurangnya investor yang masuk, sehingga promosi dan pemberdayaan objek wisata hanya dikelola oleh pemerintah setempat dengan pengetahuan yang tebatas serta anggaran dana negara yang terbatas

4) Kurangnya promosi yang dilakukan pemerintah setempat untuk mempromosikan tempattempat pariwisata di Papua, khususnya Jayapura.

5) Minimnya pengetahuan ilmu desain dalam membuat suatu promosi baik itu buku, poster, brosur, website dan lain-lain. 


\section{Analisis SWOT Pengembangan Kepariwisataan Kabupaten Jayapura}

\section{Tabel 1. Analisis SWOT Pengembangan Kepariwisataan Kabupaten Jayapura}

\begin{tabular}{|c|c|c|c|c|}
\hline Faktor-Faktor & Nilai & Bobot & Raking & $\begin{array}{c}\text { Nilai } \\
\text { Tertimbang }\end{array}$ \\
\hline \multicolumn{5}{|l|}{ Kekuatan } \\
\hline Daya tarik wisata & + & 0,04 & 4 & 0,16 \\
\hline Pesona Wisata & + & 0,04 & 4 & 0,16 \\
\hline Keasrian alam wisata & ++ & 0,05 & 4 & 0,20 \\
\hline Keragaman wisata pantai & ++ & 0,05 & 4 & 0,20 \\
\hline Pemandangan yang asri & ++ & 0,05 & 4 & 0,20 \\
\hline Atraksi budaya & ++ & 0,05 & 4 & 0,20 \\
\hline Sifat keterbukaan masyarakat & ++ & 0,05 & 4 & 0,20 \\
\hline Tersedianya penginapan & ++ & 0,05 & 4 & 0,20 \\
\hline \multicolumn{5}{|l|}{ Kelemahan } \\
\hline Kurangnya sarana dan prasarana & - & 0,02 & 1 & 0,02 \\
\hline \multicolumn{5}{|l|}{ Prasarana jalan menuju wisata belum bisa } \\
\hline lancar & - & 0,02 & 1 & 0,02 \\
\hline Kurangnya akomodasi & - & 0,02 & 1 & 0,02 \\
\hline Kekurangnya sarana penginapan & & 0,02 & 1 & 0,02 \\
\hline \multicolumn{5}{|l|}{ Peluang } \\
\hline Peluang wisatawan yang datang & + & 0,05 & 4 & 0,20 \\
\hline Peluang usaha wisata & + & 0,05 & 4 & 0,20 \\
\hline Dibangun pusat informasi wisata & + & 0,05 & 4 & 0,20 \\
\hline Pemberdayaan masyarakat & + & 0,05 & 4 & 0,20 \\
\hline Dibangunnya ekonomi wisata & + & 0,05 & 4 & 0,20 \\
\hline Adanya perhatian dari pemerintah & + & 0,05 & 4 & 0,20 \\
\hline \multicolumn{5}{|l|}{ Ancaman } \\
\hline Kurangnya tempat penginapan & - & 0,04 & 1 & 0,04 \\
\hline \multicolumn{5}{|l|}{ Adanya persaingan wisata dari Raja Ampat } \\
\hline Kab. Sorong & - & 0,04 & 1 & 0,04 \\
\hline Belum memiliki pusat informasi & - & 0,04 & 1 & 0,04 \\
\hline Sumber daya manusia kurang & - & 0,04 & 1 & 0,04 \\
\hline $\begin{array}{l}\text { Kurangnya kesadaran masyarakat akan } \\
\text { potensi wisata }\end{array}$ & - & 0,04 & 1 & 0,04 \\
\hline Kurangnya minat wisatawan & - & 0,04 & 1 & 0,04 \\
\hline Total & & 1,0 & & 0,82 \\
\hline
\end{tabular}

\section{a. Kekuatan}

1) Daya tarik wisata, berupa wisata alam, terutama pantai yang ada di Kabupaten Jayapura

2) Pesona Wisata, yang indah
3) Keasrian alam wisata yang belum terkena polusi

4) Keragaman wisata pantai, banyaknya pantai yang tersebar di wilayah Kabupaten Jayapura

5) Pemandangan yang asri 
6) Atraksi budaya dari berbagai daerah yang mengelilingi wisata di Kabupaten Jayapura

7) Sifat keterbukaan masyarakat di wilayah Kabupaten Jayapura.

8) Tersedianya penginapan yang ada di area wisata yang ada di Kabupaten Jayapura

\section{b. Kelemahan}

1) Kurangnya sarana dan prasarana di area wisata pantai yang ada di Kabupaten Jayapura.

2) Prasarana jalan menuju wisata belum bisa lancar, dikarenakan banyak jalan yang rusak menuju area wisata yang ada di Kabupaten Jayapura.

3) Kurangnya akomodasi bagi para wisatawan yang datang berkunjung di wilayah Kabupaten Jayapura.

4) Kekurangnya sarana penginapan di lokasi wisata di Kabupaten Jayapura.

\section{c. Peluang}

1) Peluang wisatawan yang datang di arena wisata yang ada di Kabupaten Jayapura.

2) Peluang usaha wisata di daerah wisata di Kabupaten Jayapura.
3) Dibangun pusat informasi wisata di area wisata, atau di pusat Kabupaten Jayapura.

4) Pemberdayaan masyarakat yang ada di wilayah wisata Kabupaten Jayapura, hal ini dilakukan untuk memberikan pendapatan bagi warga di sekitar lokasi wisata.

5) Dibangunnya ekonomi wisata, berupa di bukanya toko souvenir dimana terdapat kerajinan dari daerah Kabupaten Jayapura

6) Adanya perhatian dari pemerintah, berupa pembangunan sarana dan prasana menuju lokasi wisata yang ada di Kabupaten Jayapura.

\section{d. Ancaman}

1) Kurangnya tempat penginapan yang menyebabkan kurangnya minat wisatawan yang datang berkunjung di wisata yang ada di Kabupaten Jayapura.

2) Adanya persaingan wisata dari Raja Ampat Kabupaten Sorong

3) Belum memiliki pusat informasi di wilayah Kabupaten Jayapura.

4) Sumber daya manusia kurang, dalam hal ini pemandu wisata. 
5) Kurangnya kesadaran masyarakat akan potensi wisata yang ada di Kabupaten Jayapura.

6) Kurangnya minat wisatawan, diakibatnya kurang sarana dan prasana yang ada di lokasi wisata yang ada di Kabupaten Jayapura.

Dalam pembahasan ini peneliti akan menganalisa keadaan pemasaran pariwisata di Kabupaten Jayapura dengan menggunakan analisis SWOT. Dengan analisis ini diharapkan akan diketahui apa saja yang menjadi kekuatan, kelemahan, peluang dan ancaman pariwisata di Kabupaten Jayapura. Pengkajian tentang kekuatan dan kelemahan ini merupakan kegiatan mawas diri dan menentukan kesuksesan atau keberhasilan dalam pengembangan pariwisata. Dengan analisis kekuatan dan kelemahan dapatlah dilihat peluang dan ancaman yang mungkin muncul dan dihadapi, sehingga pengembangan strategi pariwisata di Jayapura ada pada kuadran I, yaitu : mendukung strategi agresif, hal ini dapat dilakukan dengan cara 1) dengan membenahi potensi Jayapura maka perlu dilakukan promosi wisata, 2)Dengan promosi yang ada, yang dilakukan adalah membenahi strategi pemasaran wisata yang ada di Jayapura. 


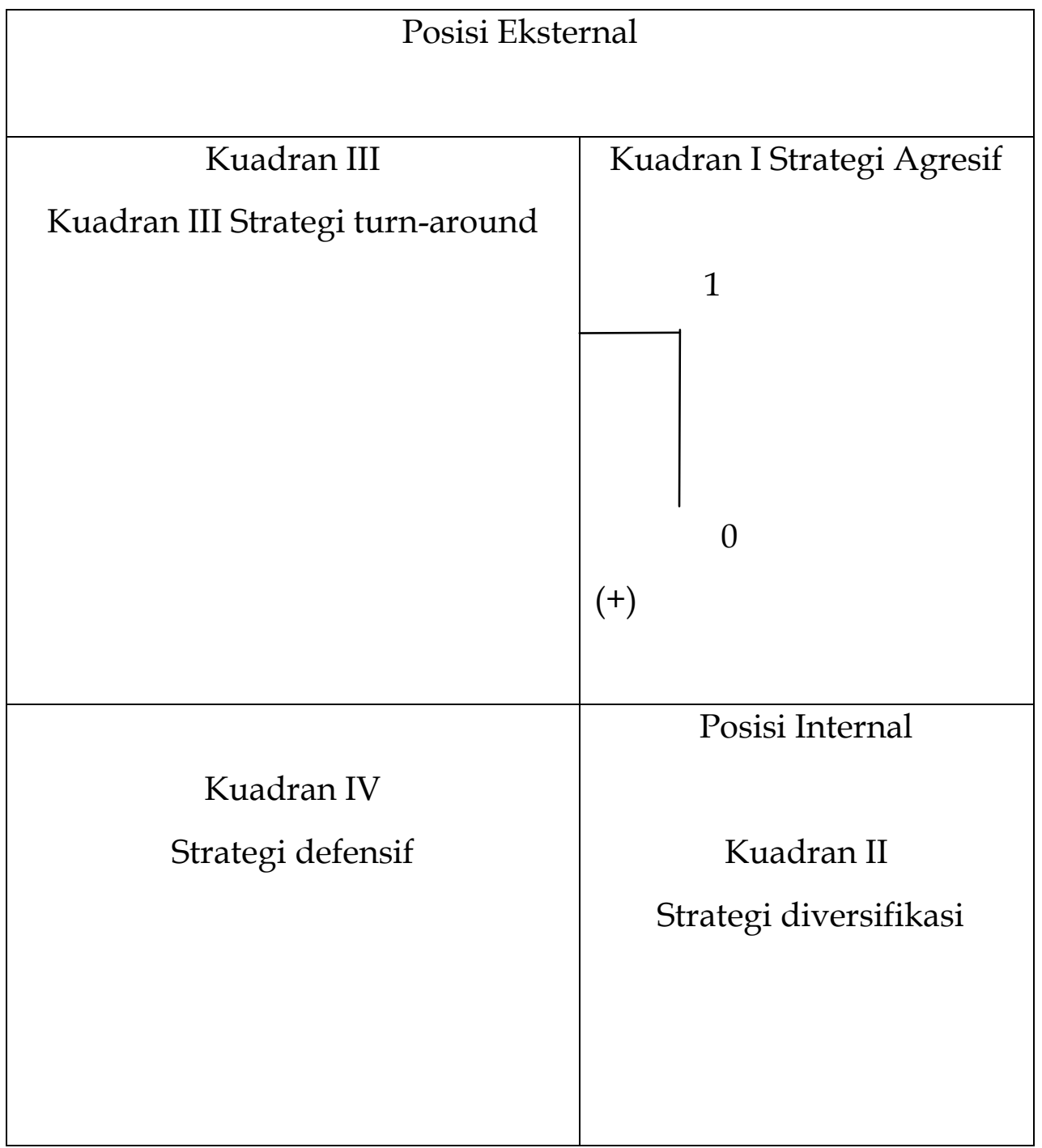

Gambar 1. Matrik Posisi Pariwisata di Jayapura

Berdasarkan pada matriks posisi yang ditunjukkan pada gambar 1 di atas bahwa posisi kepariwisataan Kabupaten Jayapura berada pada kuadran I. Ini merupakan situasi yang sangat menguntungkan karena memiliki kekuatan dan peluang yang dapat dimanfaatkan guna memasarkan potensi pariwisata yang ada di Kabupaten Jayapura. Strategi yang harus diterapkan dalam kondisi ini adalah agresif. Strategi agresif merupakan strategi yang diterapkan untuk mendukung kebijakan pertumbuhan yang agresif, dimana dapat dilakukan dengan 
mengembangkan produk dengan memanfaatkan potensi wisata yang dimiliki oleh Kabupaten Jayapura, meningkatkan kualitas jasa yang ditawarkan serta meningkatkan akses ke pasar yang lebih luas.

Strategi ini berupaya untuk memanfaatkan kekuatan yang dimiliki perusahaan untuk memperoleh peluang maksimal yang ada. Strategi yang dapat diterapkan kepariwisataan Kabupaten Jayapura dalam kuadran ini diantaranya :

a. Mengkemas paket wisata dalam berbagai harga dan varian. Adanya atraksi wisata yang sangat banyak tersebar di seluruh Kabupaten Kabupaten Jayapura, maka perlu adanya pengemasan paket wisata yang melibatkan semua tempat atraksi wisata yang ada. Pengembangan pariwisata juga perlu dilakukan secara seimbang sehingga semua daerah yang ada di Kabupaten Jayapura dapat berkembang. Perlu pengemasan paket wisata di setiap wilayah, sehingga semua daya tarik wisata yang ada dapat dikenal oleh wisatawan. Berdasarkan hasil temuan dilapangan, banyak ditemukan daya tarik wisata berupa kesenian daerah seperti tari-tarian yang belum banyak dikenal oleh umum terutama wisatawan. Untuk itu perlu adanya adanya paket wisata yang juga memasukkan seni budaya masyarakat ke dalam paket. Wisatawan selain melihat keindahan alam juga disuguhkan seni pertunjukkan yang merupakan kesenian khas daerah Kabupaten Jayapura. Untuk mampu mendatangkan wisatawan, tentu tidak lepas dari peranan pemandu wisata yakni guide yang mengantar wisatawan sampai ke tempat tujuan. Guide fee ternyata menjadi sesuatu yang sangat penting untuk mendatangkan wisatawan. Dengan adanya pemberian tips kepada pemandu wisata yang mau membawa wisatawan ke suatu objek wisata, akomodasi atau fasilitas wisata lainnya mampu membawa pengaruh baik terhadap tingkat 
kunjungan wisatawan. Namun sisi lain, dengan adanya pemberian tips kepada pemandu wisata tentu akan mempengaruhi harga sebuah produk wisata. Oleh karenanya, perlu adanya pembedaan harga produk antara harga lokal dan harga wisatawan. Dengan pembedaan harga tersebut maka pengelola objek dan fasilitas wisata tetap bisa beroperasional karena dengan harga lokal masyarakat umum pun bisa datang dan menikmati produk wisata yang dijual, dan dengan harga wisatawan bagi siapapun yang mampu membawa tamu akan memperoleh tips sehingga dapat menjadi motivasi bagi pemandu untuk mendatangkan wisatawan sebanyak-banyaknya dan tentunya akan memberikan keuntungan bagi Kabupaten Jayapura.

b. Strategi menciptakan program yang berbasis budaya lokal dan ramah lingkungan. Berdasarkan hasil identifikasi potensi wisata yang dilakukan di Kabupaten Jayapura, daya tarik yang dimiliki oleh
Kabupaten Jayapura tidak kalah dengan daerah lainnya yang ada di wilayah Papua bagian selatan, sehingga produk wisata yang ditawarkan lebih beragam. Hanya saja pengelolaan dan pengembangan produknya dengan menyajikannya ke dalam bentuk program wisata belum dilakukan secara maksimal, sehingga membuat atraksi wisata yang ditawarkan terkesan monoton dan terkadang hampir sama dengan penawaran atraksi wisata di wilayah Papua bagian selatan. Kabupaten Jayapura dalam hal ini harus memproklamirkan image atau karakteristik

c. Kepariwisataannya sendiri sehingga mampu membedakannya dengan daerah lainnya, namun tetap pada pengembangan pariwisata budaya yang bersendikan kebudayaan masyarakat lokal seperti yang dicanangkan oleh pemerintah daerah Papua, misalnya peninggalan sejarah yang ada di Jayapura, hal ini merupakan icon yang tepat untuk digunakan 
melihat banyaknya bangunan bersejarah peninggalan penjajah belanda yang ditemukan di Kabupaten Jayapura.

d. Strategi memanfaatkan teknologi dalam operasional sehingga mudah dalam memberikan pelayanan. Perkembangan teknologi yang semakin cepat merupakan salah satu peluang untuk memberikan kemudahan dari pengelola dalam memberikan pelayanan terhadap konsumen yang dalam hal ini adalah wisatawan. Pemanfaatan teknologi di Kabupaten Jayapura bisa dikatakan masih jauh minimnya dengan pemanfaatan teknologi yang dilakukan di wilayah Papua bagian Selatan dimana teknologi benar-benar dimanfaatkan sehingga menjadi lebih tepat guna. Hal ini terlihat dalam pemanfaatan media internet, dimana setiap hotel atau atraksi wisata memiliki web tersendiri maupun terkoordinasi dengan baik dibawah naungan suatu lembaga. Informasi yang disajikan memang benar sesuai adanya dan setiap ada perubahan akan dilakukan up-date informasi, sehingga wisatawan mendapatkan informasi yang riil terjadi di lapangan. Kondisi ini akan berimplikasi positif terhadap tingkat kepuasan konsumen, dimana kepuasan dapat tercapai apabila harapan sesuai dengan kenyataan. Selain itu untuk kegiatan operasional di hotel salah satu contoh pemanfaatan teknologi adalah dalam kegiatan reservasi yang dulunya masih dilakukan secara manual sekarang dapat dilakukan secara on-line lewat web yang dibuat oleh masing-masing hotel. Utamanya untuk infromasi pariwisata perlu adanya informasi tentang objek dan daya tarik wisata yang tersebar di seluruh Kabupaten Jayapura.

Sesungguhnya Kabupaten Jayapura memiliki banyak potensi wisata, namun karena keberadaannya yang cukup jauh dari kota dan kurangnya informasi tentang keberadaan daya tarik diterima oleh pelaku pariwisata dan pemda khususnya, maka daya tarik tersebut 
hanya berkembang secara pribadi dan pengelolaanya tidak dilakukan secara optimal. Untuk itu perlu adanya perhatian terhadap daerah-daerah yang berpotensi untuk dikembangkan sebagai daya tarik wisata dengan tetap melibatkan peranan masyarakat sebagai pemilik daerah tersebut. Dalam penelitian ini salah satu produk yang dihasilkan adalah sistem informasi tentang objek dan daya tarik wisata yang tersebar di desa-desa pada sembilan kecamatan yang ada di Kabupaten Kabupaten Jayapura.

Potensi wisata alam terutama wisata baharinya menawarkan keeksotikan yang menakjubkan. Jika berkunjung ke Jayapura, sempatkan diri untuk melongok sejenak ke pantai yang eksotik ini. Pantai ini berada di Desa Tablanusu, Distrik Depepre, Kabupaten Jayapura, Propinsi Papua. Namanya Pantai Harlem.

Banyak orang mengatakan bahwa Pantai Harlem merupakan pantai tercantik di Jayapura. Namun letak pantai ini terpencil dan belum banyak wisatawan yang berkunjung ke pantai ini. Jadi bila kita berkunjung ke pantai ini, akan terasa memiliki pantai pribadi karena belum tentu setiap harinya ada wisatawan yang berkunjung ke Pantai Harlem.

Pantai Harlem memiliki pasir putih dan air laut sangat jernih dan bergradasi indah. Ombak di pantai ini pun tidak terlalu besar karena pantai ini merupakan wilayah teluk, sehingga cocok bagi pecinta snorkeling. Terumbu karang, ikan laut dan biota laut lainnya dapat kita saksikan saat snorkeling di Pantai Harlem. Tidak perlu snorkeling sampai ke tengah laut untuk melihat keindahan bawah laut Pantai Harlem ini. Beberapa meter dari bibir pantai pun sudah menawarkan snorkeling spot yang indah.

Selain snorkeling, kita juga bisa memancing, berenang, bermain pasir, atau hanya sekedar menikmati keindahan Pantai Harlem yang mempesona. Terdapat kolam air tawar di dekat Pantai Harlem yang dapat digunakan untuk membilas diri selesai bermain-main di pantai. Kolam air tawar ini airnya masih alami, jernih dan bersih. 
Pantai Harlem hanya bisa dijangkau melalui jalur laut. Jika ingin ke Pantai Harlem harus melalui Dermaga Depepre terlebih dahulu. Dermaga Depepre berjarak sekitar 48 $\mathrm{km}$ dari Kota Jayapura atau $22 \mathrm{~km}$ dari Kota Sentani. Dari Dermaga Depepre kita bisa menyewa perahu motor menuju Pantai Harlem dengan waktu tempuh sekitar 15 menit. Perahu yang disewakan mempunyai kapasitas maksimal 10 orang dengan tarif sekitar Rp. 300.000 - 400.000 per perahu untuk pulang pergi.

\section{KESIMPULAN}

Berdasarkan hasil analisis dan pembahasan yang telah diuraikan sebelumnya, maka kesimpulan terhadap pengembangan kawasan wisata Kabupaten Jayapura adalah sebagai berikut :

1. Faktor-faktor internal yang mendukung pengembangan pariwisata Kabupaten Jayapura adalah : Daya tarik wisata, berupa wisata alam, terutama pantai yang ada di Kabupaten Jayapura, Pesona Wisata, yang indah, Keasrian alam wisata yang belum terkena polusi, Keragaman wisata pantai, banyaknya pantai yang tersebar di wilayah Kabupaten Jayapura, Pemandangan yang asri, Atraksi budaya dari berbagai daerah yang mengelilingi wisata di Kabupaten Jayapura.

2. Faktor-faktor eksternal yang mendukung pengembangan pariwisata Kabupaten Jayapura, antara lain : Peluang usaha wisata di daerah wisata di Kabupaten Jayapura, Dibangun pusat informasi wisata di area wisata, atau di pusat Kabupaten Jayapura, Pemberdayaan masyarakat yang ada di wilayah wisata Kabupaten Jayapura, hal ini dilakukan untuk memberikan pendapatan bagi warga di sekitar lokasi wisata, Dibangunnya ekonomi wisata, berupa di bukanya toko souvenir dimana terdapat kerajinan dari daerah Kabupaten Jayapura, Adanya perhatian dari pemerintah, berupa pembangunan sarana dan prasana menuju lokasi wisaya yang ada di Kabupaten Jayapura. 
3. Faktor penghambat pariwisata Kabupaten Jayapura : Kurangnya sarana dan prasarana di area wisata pantai yang ada di Kabupaten Jayapura, Prasarana jalan menuju wisata belum bisa lancar, dikarenakan banyak jalan yang rusak menuju area wisata yang ada di Kabupaten Jayapura, Kurangnya akomodasi bagi para wisatawan yang datang berkunjung di wilayah Kabupaten Jayapura, Kekurangnya sarana penginapan di lokasi wisata di Kabupaten Jayapura.

\section{DAFTAR PUSTAKA}

Andreas Adiwardana. 1999. Pusaka Budaya \& Pariwisata. Pustaka Larasan: Denpasar.

Bryson dalam Marzuki. 2006. Strategi Managemen (Manajemen Strategi).Salemba Empat, Jakarta.

Coleman dalam Moekijat. 2007. Sistem Informasi Manajemen. Andi. Yogyakarta.

Effendy. M. 1989. Pengantar Ilmu Pariwisata. Yogyakarta: ANDI.

George M. Scott yang diterjemahkan oleh Budiman. 2001. Sistem Informasi manajemen. BPFE. Yogyakarta,
Hafidiah, M. 2003. Strategi Pengembangan Wisata. BPFE. Bandung.

Hadayaningrat, I. 1996. Pengantar Manajemen. Pustaka Ilmu. Yogyakarta.

Iman Sudarman. 2003. Sistem Informasi Manajemen. Rajagrafindo. Jakarta.

Oemar Hamalik. 1993. Sistem Pengembangan Sektor Pariwisata Perspektif Manajemen Strategik Sektor Publik. YPAPI: Yogyakarta.

Rangkuti, 2008. Manajemen Informasi. BPFE. Bandung.

Siagian. 2004. Pengantar Manajemen. Dian Ilmu. Yogyakarta.

Susanto.A. 2002. Sistem Strategis Pemasaran Daerah Tujuan Wisata. Pradnya Paramita: Jakarta

Undang-Undang Nomor 10 Tahun 2009 tentang Kepariwisataan 